abnormal in individuals with an inborn tendency to psoriasis, thus after an interval of 10 to 15 days producing the lesions of psoriasis (Whyte and Baughman, 1964). An antigen-antibody reaction centred on the dermal capillaries, similar to that which occurs in the glomerular capillaries in acute nephritis, seems unlikely, as fluorescent antibody studies carried out on psoriatic skin have been negative (Raskin, 1964).

Pyoderma in patients with seborrhoeic eczema is a very common complication; it is much rarer in atopic eczema, yet 4 out of 492 patients suffering from atopic eczema were found to have glomerulonephritis on presentation (Roth and Kierland, 1964). Impetigo has been reported as a common precursor of glomerulonephritis in the U.S.A. (Blumberg and Feldman, 1962). This could be true in this country: over the past two years in our department half the cultures from 24 patients with impetigo grew beta-haemolytic streptococci.

It is interesting that two of our patients (Cases 3 and 6) had acute rheumatism in adolescence-a further manifestation of their streptococcal hypersensitivity.

\section{Summary}

Nephritis may occur with common skin diseases. Examples of various types of nephritis associated with anaphylactoid purpura, erythema multiforme, erythema nodosum, acute guttate psoriasis, and infected eczema are given.

We are grateful for the belp of Drs. H. J. Wallace, G. C. Wells, and E. W. Prosser Thomas.

\section{REFERENCES}

Blumberg, R. W., and Feldman, D. B. (1962). f. Pediat., 60, 677.

Comaish, J. S., and Kerr, D. N. S. (1961). Brit. med. F., 2, 84.

Heptinstall, R. H., and Joekes, A. M. (1963). In Diseases of the Kidney, edited by M. B. Strauss and L. G. Welt. Churchill, London.

James, D. G. (1961). Brit. med. 3., 1, 853.

Ludlam, G. B., Bridges, J. B., and Benn, E. C. (1964). Lancet, 1, 958.

Milne, M. D. (1962). In Renal Disease, edited by D. A. K. Black, p. 463. Blackwell, Oxford.

Nørholm-Pedersen, A. (1952). Acre derm.-venereol. (Stockh.), 32, 159.

Norrlind, R. (1950). Ibid.. 30, 64.

Peters, J. H. (1963). In Diseases of the Kidney, edited by M. B. Strauss and L. G. Welt. Churchill, London.

Rammelkamp, C. H. (1\%2), In Renal Disease, edited by D. A. K. Black, p. 173. Blackwell, Oxfond.

Raskin, J. (1964). Arch. Derm., 84, 569.

Roth, H. L., and Kierland. R. R. (1964). Ibid., 89, 209.

Whyte, H. J., and Baughman. R. D. (1964). Ibid., 89, 350.

Whyte. H. J., and Baughman, R. D. (1964), Ibid., 89, 350.
Wilson. C. (1962). In Renal Dicease, edited by D. A. K. Black, p. 188. Blackwell, Oxford.

Winkelmann, R. K., and Dite, W. B. (1964). Medicine (Baltimore), 43, 59.

Yaffee, H. S., and Stargardter, F. (1963). Arch. Derm., 87, 601.

\title{
Variations in Small-intestinal Villous Shape and Mucosal Dynamics
}

\author{
B. CREAMER,* M.D., M.R.C.P.
}

Brit. med. .., 1964, 2, 1371-1373

The small-intestinal mucosa maintains a constant appearance while being in a continuous state of proliferation and loss. The crypts of Lieberkühn contain immature cells showing frequent division, and from them epithelial cells stream up the villi in a regular fashion to be lost at the tips (Leblond and Stevens, 1948 ; Creamer et al., 1961). The whole smallintestinal epithelium is replaced in this way about every two days. The rates recorded by observers using many animal species have been remarkably constant, and in man Bertalanffy and Nagy (1961) have estimated the duodenal turnover time to be two days. If the production of new cells is abruptly stopped by either antifolic drugs or $x$-irradiation the normal villous structure collapses (Philips and Thiersch, 1949 ; Wiernik et al., 1962). Within two to three days sheets of epithelial cells are shed and stunted broad villi or a flattened surface is left. This suggests that the structure of the small-intestinal mucosa is plastic and that variations in epithelial-cell turnover may well determine the shape and size of the villi.

The so-called normal appearance of the small-intestinal villi as viewed under the dissecting microscope is fingershaped, but many healthy people show some leaf-shaped villi. In pathological conditions a whole range of appearances is seen, from normal finger villi to leaves, to convolutions, and in some cases to a completely flat mucosa (Holmes et al., 1961). The purpose of the present study was to see if the change in villous shape from fingers to convolutions could have an explanation in the dynamics of the intestinal epithelial cells. The problem of idiopathic steatorrhoea and the production

\footnotetext{
* Consultant Physician, St. Thomas's Hospital, London.
}

of a flat mucosa has been considered previously (Creamer, 1962).

\section{Materials and Methods}

Twenty small-intestinal biopsies were examined. They were selected solely because they showed a variety of changes from finger villi to convolutions. None of the patients had idiopathic steatorrhoea, but some had gastrectomies, Crohn's disease, or other intestinal disease. Seventeen were obtained perorally and three were surgical specimens, of which two came from the jejunim at a gastrectomy and a gastroenterostomy stoma under revision.

The sections were all well orientated, so that the crypts were cut longitudinally. On each section a count was made of at least 2,000 epithelial cells, recording separately crypt cells, adult cells, and metaphase mitotic figures. From this the ratio of adult cells to crypt cells was calculated. The mitotic rate was expressed as metaphases per hundred crypt cells.

Where leaf-shaped villi are present the section may be cut through the long axis of the leaf $A-A$ or across the short axis B-B (Fig. 1). If a cell count is made through a long axis A-A fewer adult cells are recorded than if a number of leaves are cut through the short axis B-B. In one case this was done, and the proportion of adult cells to crypt cells was exactly half when a leaf villus was cut down the long axis compared with a similar area where the leaves were sectioned through the short axis. Because of this, an area was always chosen where leaf-like villi were sectioned through the short axis.

The crypt length was estimated by counting the number of cells down one side of a crypt, the average of several crypts 
always being taken. The histological sections were then photographed and the total mucosal height was calculated. After this the specimens were removed from the blocks and examined under the dissecting microscope so that an exact comparison could be made between the cell counts and the surface appearance next to the section. The dissecting



Fig. 1.-Diagram showing how leaf-shaped villi may be sectioned down the long axis $A-A$ or across the short axis $B-B$.

microscope appearances were graded as follows : grade 1; finger villi; grade 2, finger villi and leaf-shaped villi mixed; grade 3, leaf-shaped villi ; and grade 4, ridged convolutions.

\section{Results}

Five parameters were available for each specimen: the dissecting-microscope appearance, the mucosal height, the adult-cell to crypt-cell ratio, the crypt length, and the mitotic rate. When the specimens were graded according to the dissecting-microscope appearances there was an obvious correlation with the adult-cell to crypt-cell ratio (Fig. 2).

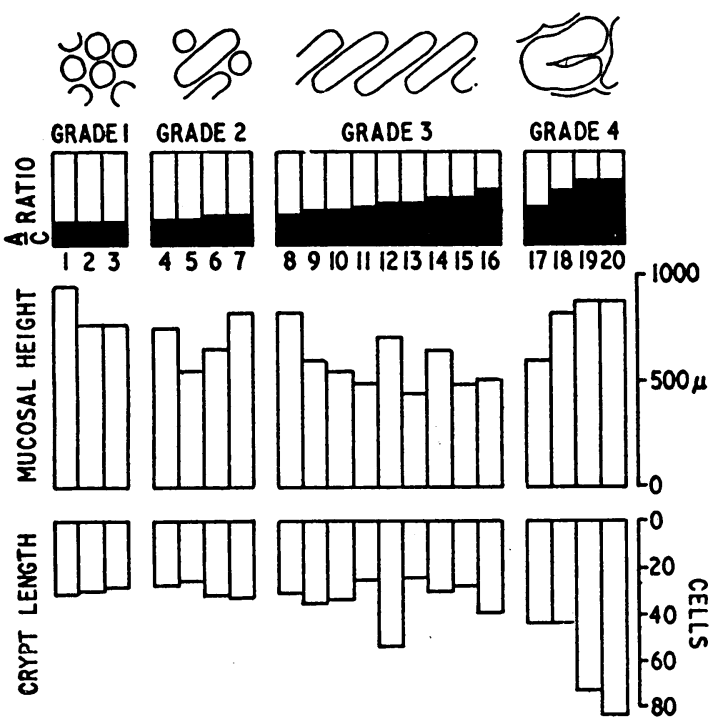

FIG. 2.-Diagrammatic representation of data on dissectingmicroscope appearance, adult-cell to crypt-cell ratio, total mucosal height, and crypt length in 20 specimens.

Normal finger-shaped villi have, on average, a ratio of 3 adult cells to 1 crypt cell, while specimens with leaf-shaped villi have a ratio of 1.4 adult cells to 1 crypt cell, and specimens with a convoluted appearance 1 adult cell to 1.4 crypt cells.

This ratio gives an idea of the distribution of epithelial cells on one surface of the sectioned specimen, but mucosae have a complicated three-dimensional shape. It would be extremely informative to know the total number of cells covering the villi of a given area of mucosa. This cannot yet be measured, but a rough estimate can be calculated so that the population of adult cells clothing one mucosa can be compared with another. The ratio of adult cells is multiplied by the height of the mucosa and corrected by a factor for the surface area of various villous shapes (Fig. 3). This factor was derived from cubist drawings of the various villous shapes and is
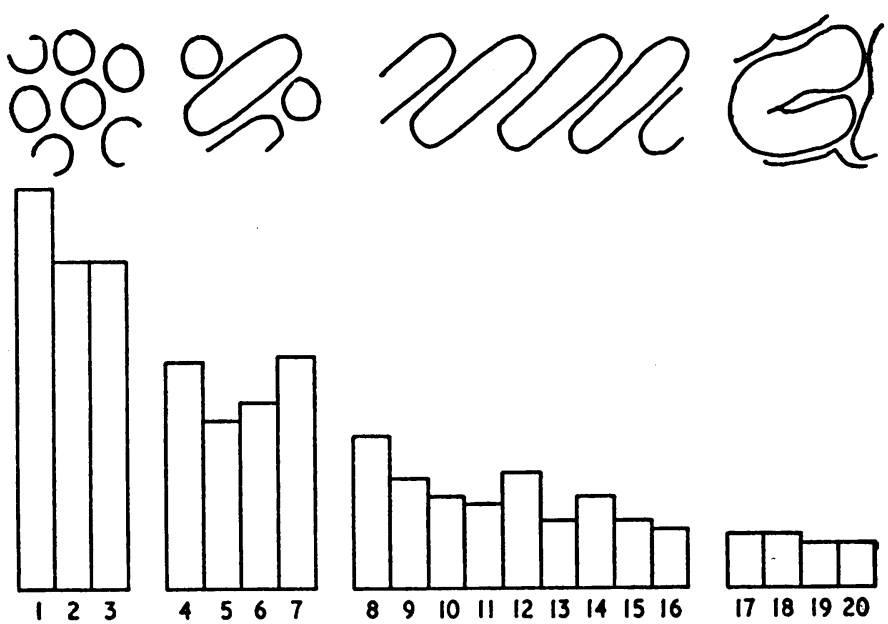

FIG. 3.-Diagram of relative adult-cell population estimated for each specimen.

clearly only an approximation (finger villous surface area $100 \%$, leaf villi $50 \%$, convolutions $25 \%$ ). It will be seen that as villi become more abnormal there is a striking reduction in the total number of epithelial cells ; leaf-shaped villi. have only about a quarter of the number of cells compared with the normal, and convolutions only an eighth.

If the overall mucosal height is next considered it will be seen that some mucosae are comparatively thinner than $\mathbb{Q}$ others, though even the flattest convolutions may have a $\overrightarrow{\vec{B}}$ normal total mucosal height. This division is also emphasized $\frac{9}{3}$ by the crypt length. In one pattern the total height is small and the crypt length normal or short, while the other pattern shows a normal or near normal mucosal height with long crypts. The crypts may extend to three times the normal length.

The average mitotic rate in the normal crypts was $1.1 \%$ and in the abnormal specimens $0.9 \%$. Where the crypt $\delta$ length tended to be short the mitotic rate was low and $\xi$ averaged $0.6 \%$, the lowest rate being $0.25 \%$. In those specimens where the crypts were long the mitotic rate was $N$ unchanged and averaged $1 \%$.

\section{Discussion}

The shape of villi, whether normal or abnormal, correlates well with the population of adult cells in the mucosa. Where the villi are finger-shaped the cell population is comparatively large ; but where the villi are leaf-shaped or convoluted the cell population is comparatively small. Therefore the shape of $\bar{O}$ villi seems a simple matter of economics; when abundant $\overrightarrow{\mathbb{D}}$ cells are available fingers are formed, but when few cells are $\frac{\vec{D}}{\mathbb{Q}}$ available leaves and ridges are the necessary means of building projecting structures. It is probable that villi are continually being broken and repaired, and during this process the balance 8 of cells produced and lost dictates the villous shape.

The next problem is why the adult-cell population is diminished in these cases. In the small intestine the cells are? turned over so rapidly that it is useful to consider analogies with another system where cells are also continuously 
replenished, the blood. Here haemolysis, aplasia, and maturation arrest are common concepts. There seems good reason to believe that exactly similar mechanisms exist in the small intestine. Evidence has previously been produced to suggest that the mucosa in idiopathic steatorrhoea is flattened because of a maturation arrest of crypt cells (Creamer, 1962). In the present study some mucosae showed a small population of adult cells but an increased population of crypt cells. The rate of division is not in excess, but the number of cells dividing may be as much as three times that in health, so the output of cells from the crypts will be similarly increased. Loss must equal output if a steady state is to be maintained, and therefore the surface cells will be shed at a similarly increased rate. There is evidence of excessive cell death and desquamation on the villous tips of many of these specimens but no evidence of cell death in the crypts as is seen in flat mucosae from idiopathic steatorrhoea and other conditions. This seems to be analogous to haemolysis or haemorrhage, the crypts (marrow) hypertrophying in response to the excess loss. However, the other group of abnormal mucosae had crypts of a normal or shorter length than in health and a diminished mitotic rate. Here the small adultcell population is probably the result of a small output of cells and represents a relative atrophy or hypoplasia. The patients in this group had chronic wasting illnesses such as pulmonary tuberculosis and temporal arteritis.

These observations introduce two factors of importance to absorption. The abnormal mucosae are considerably short of adult epithelial cells, so that the area available for absorption is diminished. It is important to realize that many of these specimens look comparatively normal on an ordinary histological section. If these findings applied to the whole mucosa the small-intestinal surface might be reduced to 25 to $12 \%$ of normal. There is, however, considerable variation in some conditions between the changes on the crests of mucosal folds to the more sheltered troughs in between them, and it is unwise to generalize from a single peroral biopsy (Creamer, 1964). The second factor is the maturity of the adult epithelial cells covering the villi. In the changes akin to haemolysis the cells must pass through the adult population much faster than in health. If normal adult epithelial cells have a life of about two days, those on a "haemolytic" mucosa may last only a few hours and therefore the cells available for absorption will be younger than in health. This may mean that their enzymatic complement is below normal in addition to their small number.

\section{Summary}

Twenty specimens of small-intestinal mucosa showing variations in villous shape from fingers to leaves and to convolutions have been examined. As the villous shape becomes more abnormal the adult epithelial cells covering them are greatly reduced in number. It is suggested that the villous shape is plastic and remoulds to a more simple and economical shape as adult cells become fewer. There are two abnormal patterns of cell turnover associated with the diminution of adult epithelial cells; one is analogous with haemolysis and the other with hypoplasia.

I am grateful to Dr. D. J. McBrien and Dr. W. Hindle for obtaining some of the specimens and to Mr. P. J. Leppard for technical assistance.

\section{REFERENCES}

Bertalanffy, F. D., and Nagy, K. P. (1961). Acta anat. (Basel), 45, 362. Creamer, B. (1962). Gut, 3, 295.

- (1964). Brit. med. F., 2, 1373.

- Shorter, R. G., and Bamforth, J. (1961). Gut, 2, 110.

Holmes, R., Hourihane, D. O'B., and Booth, C. C. (1961). Lancet, 1, 81.

Leblond, C. P., and Stevens, C. E. (1948). Anat. Rec., 100, 357. . Ther., Philips, F. S., and Thiersch, J. B. (1949). S. Pharmacol.
Wiernik, G., Shorter, R. G., and Creamer, B. (1962). Gut, 3, 26

\title{
Small-intestinal Mucosal Dynamics and the Environment
}

\author{
B. CREAMER,* M.D., M.R.C.P.
}

Brit. med. 9., 1964, 2, 1373-1375

\begin{abstract}
These observations were prompted by the finding of a very abnormal jejunal mucosa near the stoma of gastric operations where the environment of the cells was clearly deranged. The small-intestinal mucosa is normally in a state of rapid turnover and might be expected to respond to changes in the environment. It has previously been shown that the structure of villi is related to the size of adult epithelial cell population, so that as the available epithelial cells decrease in number leafshaped villi or convolutions are formed as a matter of economy (Creamer, 1964). This diminution of adult cells may result from a failure of output from the crypts or an excess loss from the surface.

The cells covering the villi have a luminal environment, but they also glide over a structure which represents an environment on the basement-membrane side, and either of these environments may be altered. In this study only changes in the luminal environment and the consequent effects on cell turnover have been examined.
\end{abstract}

- Consultant Physician, St. Thomas's Hospital, London. Eleven specimens of small-intestinal mucosa were examined
from a variety of conditions. Details of the cases are men-
tioned in the results. Six of the specimens were surgical and
five were obtained perorally. Cell counts and dissecting-
microscope appearances were obtained as described
previously (Creamer, 1964).
Results
Nine specimens were examined from patients in whom the
environment of the small-intestinal mucosa was certainly
abnormal. Four had gastric operations, two chronic intestinal
obstruction from Crohn's disease, two chronic pancreatitis,
and one the Zollinger-Ellison syndrome. All were abnormal
under the dissecting microscope, having either leaf-like villi (grade 3 ) or flattened convolutions (grade 4). In all the specimens the same pattern was seen of a diminished ratio of adult cells to crypt cells and an increase in the length of the crypts 